\title{
Valuable Impulses and Successful Models of Gearbox Development from Practice
}

\author{
Tobias Schulze \\ DriveConcepts GmbH, Dresden 01067, Germany
}

\begin{abstract}
Gears play an important role in mechanical engineering because of their moment and speed transmission possibilities. Design and optimization of a complete gearbox provide many requirements to the designer. The complex gearbox model consists of many machine elements (shafts, gears, bearings, housing, seals, and shaft-hub connections). The gearbox must be understood as a system with interactive parts. Next to the calculation of kinematics, load capacities and life times of single elements, aspects of load distribution and efficiency and noise excitation of gearboxes become important. The wide range of knowhow needed mostly cannot be covered by a small number of engineers. The development of automated calculation routines with understandable and comprehensive results is the goal for these research projects that lead to software-realizing solutions for engineers to efficiently design, calculate, optimize and verify gearboxes with minimal resources in terms of calculation experts and time.
\end{abstract}

Key words: Tooth contact analysis, gearbox design and verification, finite element gearbox calculation, gear modifications/optimization, planetary gearboxes, automated calculation process.

\section{Introduction and Problems}

Calculation software proves its use and therefore its value by finding solutions for concrete problems in the practical application. This generally worded sentence also applies for the calculation package MDESIGN with numerous opportunities to support gearbox development. The tool MDESIGN is presented, as a part of the gearbox calculation and optimization based on case studies to demonstrate the value of the software package from the user's point of view, below.

Numerous service- and consulting projects over the last decade demonstrate what economic benefit the use of analytical calculation software in the product development process provides. The different tools for interpretation, for the detection, optimization and documentation must be perfectly coordinated to realize their full potential as well.

Corrsponding author: Tobias Schulze, managing director, research fields: gear design \& consulting work; development of calculation software for gear design and verification, tooth contact analysis, machine elements calculation in general; FKM analysis; FE calculations and MBS simulations.
The following article describes how the gearbox calculation package of MDESIGN supports the daily routine of engineers in selected practical case studies. The package consists of the following individual libraries:

- MDESIGN gearbox

- MDESIGN LVR

- MDESIGN LVR ${ }^{\text {planet }}$

MDESIGN gearbox offers an automated gearbox design of up to 3-stage spur gear units, 3-stage planetary gears, a bevel gear and a combination thereof. It can be developed any own gear designs using integrated gear designers (3D configuration of the transmission model). In addition, the package allows the selection of preconfigured designs on standard examples. Evidence and documentation of capacity for a single or all machine components (gears, shafts, bearings, and plain bearings) is possible according to current standards (DIN, ISO, etc).

MDESIGN LVR is the load distribution calculation for involute cylindrical gears. The calculation is performed over the whole field of contact in profile and width direction. The results of the calculation are 
displayed graphically and can be displayed for a single mesh position or the field of contact. The result of the load distribution calculation is the ratio of maximum to average load and pressure in the field of contact. In addition, the stiffness and noise characteristics for up to four-stage gearboxes can be analyzed.

MDESIGN LVR ${ }^{\text {planet }}$ allows the calculation of load distribution on the planets $\left(\mathrm{K}_{\gamma}\right)$ and load distribution in the field of contact $\left(\mathrm{K}_{\mathrm{H} \beta} / \mathrm{K}_{\mathrm{H} \alpha}\right)$ of the planets. Cyclical root stress calculation on the ring gear can be done using the integrated FE calculation. There are different methods of calculating (only load sharing/distribution on planets, load distribution and face load factor, load distribution with user specified default values of single parameters $\left(\mathrm{K}_{\mathrm{H} \beta} / \mathrm{K}_{\gamma}\right)$ and evaluation of cyclic root pressure on the ring gear). Important influences are the gear wheel deformation, the planet carrier deformation, the bearing clearance and the bearing deformation, as well as the modifications and deviations of the teeth. It is possible to obtain a proposal for optimum modification of the flank.

The following case studies are intended to provide a concrete insight into the assistance functionality of the calculation program in the product development process, the full extent of the calculation will not be presented. Rather, the specific functions and their application shall be highlighted.

MDESIGN is able to accomplish the entire development process from the first idea, through the beginning drafts and a qualified interpretation, the final strength verifications according to current standards and the documentation as well as a transfer to other CAx tools. The typical areas of a gearbox development process are shown in Fig. 1.

At first, the design process of a saw drive with an output of $3 \mathrm{~kW}$ will be presented using the automated design analysis of MDESIGN gearbox. The task of the parameter definition, variant determination, the decision-making process of the proposed solutions and the final conversion into a calculation model for verification of the chosen solution will be described.

Following the product development process, the second example shows the recalculation of an adjustment gear system with a plurality of individual machine elements according to the standards. The gears, shafts and bearings can be modeled, calculated and documented in a logical relationship to each other.

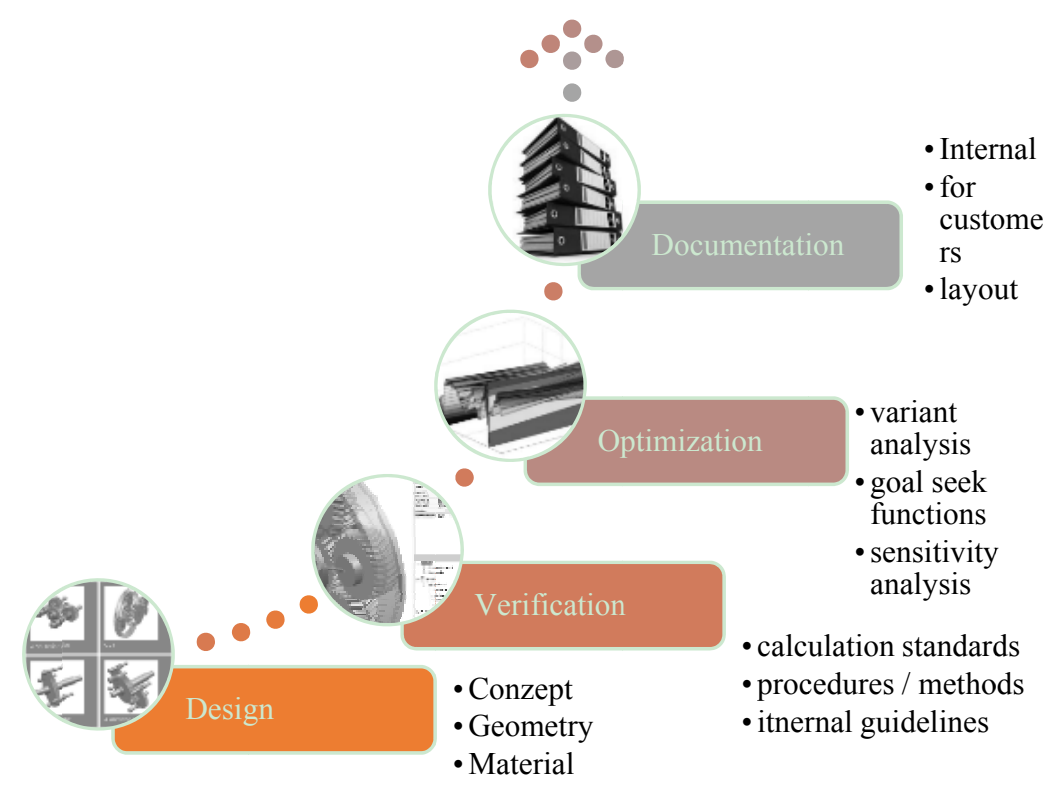

Fig. 1 Development process for drive technology. 


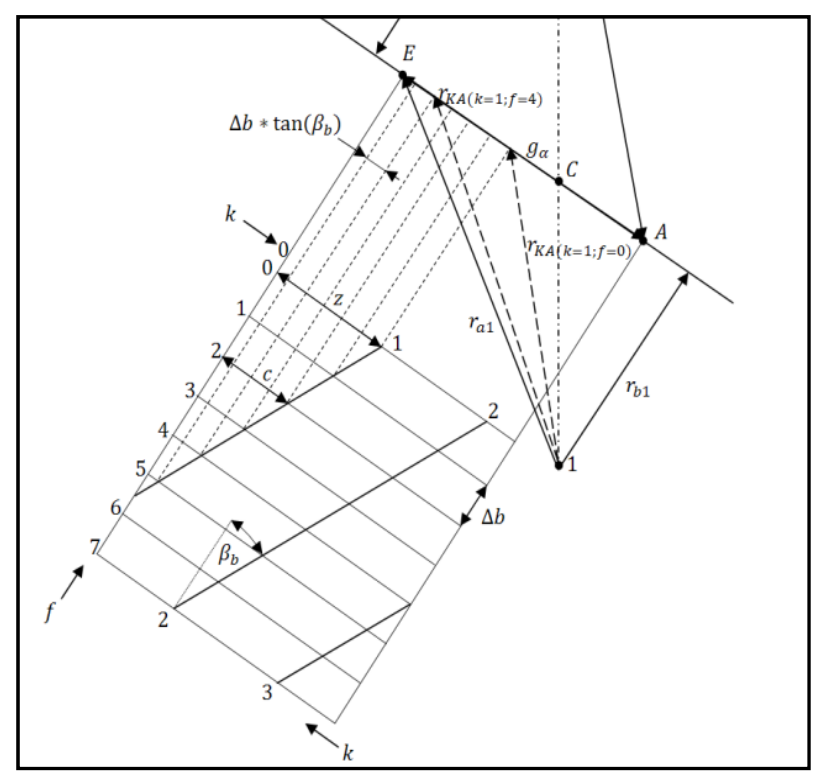

Fig. 2 Contact lines in the field of contact.

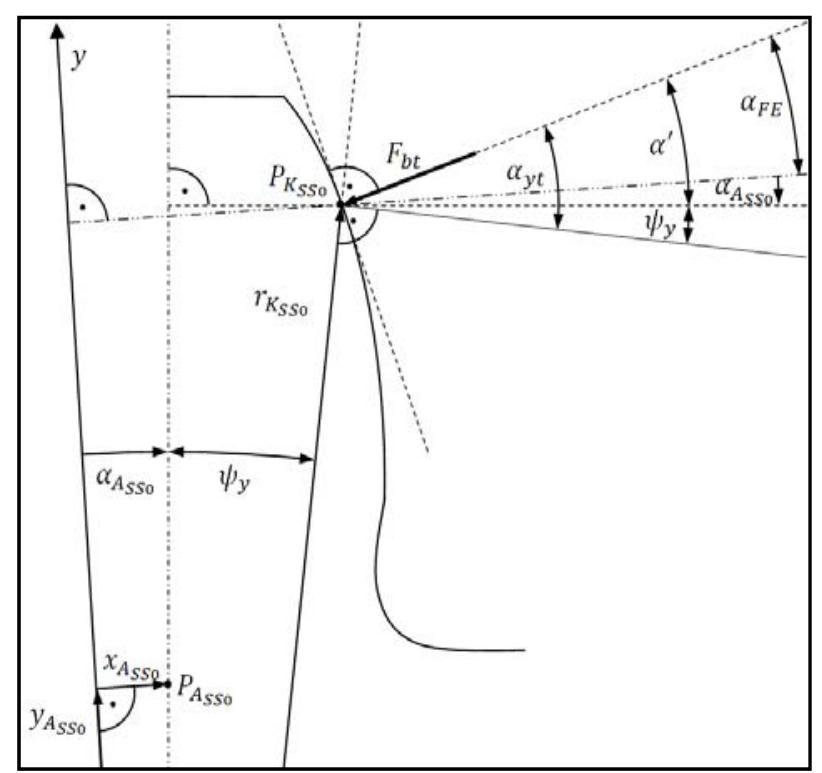

Fig. 3 Determination of tooth loads.

The task of optimizing is shown by analyzing a planetary gear with double helical gears in terms of different modifications and their effect of load-, pressure- and root stress distribution, demonstrating the minimum influence factors that have to be taken into account to obtain a practical and user orientated, relevant statement for correct flank modifications.

The last example shows the possibility of integration of the software packages in the entire CAx. This includes the control of computations in the background (batch mode) and the possibility of linking the analytical calculations with CAD systems using STEP export.

\section{Experimental Results/Verification}

The goal of the software calculation algorithm is an automated calculation process. The results are given by safety factors mostly. To verify the software results, there was the need to do the corresponding experiments. For the example of the gear calculation, the tooth contact analysis is derived by finite element calculations and the development of the influence coefficient method. Whereas calculation standards calculate machine elements with approximation coefficients the researches for the MDESIGN software are going into detail for each machine element. Looking at the tooth contact, the real contact conditions must be interpreted mathematically.

Having the mathematical model for the calculation was the first step to prepare for the following experiments. The presented experimental result demonstrates the verification of a simple spur gear stage, where the mathematical lowest safety factor was calculated at first stage of the gearbox with the result of a peak of flank pressure in tooth contact. Analyzing the tooth contact and the load distribution factor $\mathrm{K}_{\mathrm{H} \beta}$ of 1.36 , the resulting safety factor was $\mathrm{S}=$ 0.89 .

Using the automated calculation process of the developed software the needed modifications for this tooth contact could be calculated in consideration of:

- Tooth deformation;

- Shaft deformation;

- Bearing deformation;

- Housing deformation;

- Manufacturing tolerances;

- Lubrication.

Lowering the load distribution factor to $\mathrm{K}_{\mathrm{H} \beta}=1.1$ leading to a safety factor of $\mathrm{S}=1.16$ the gear contact and therefore the gearbox could be optimized and verified in one step. 


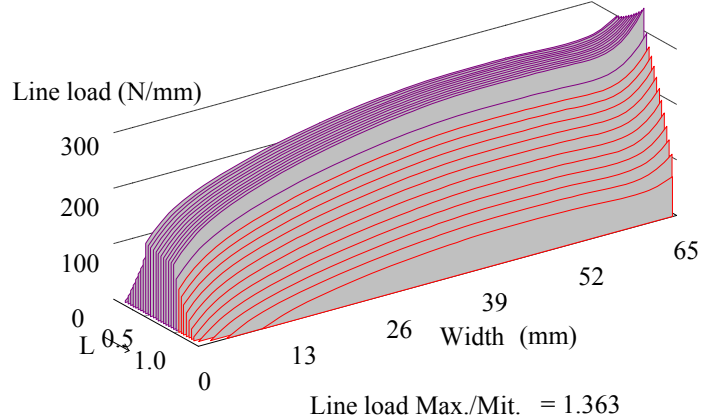

The test rig for this gearbox showed the expected damages of the tooth flanks.

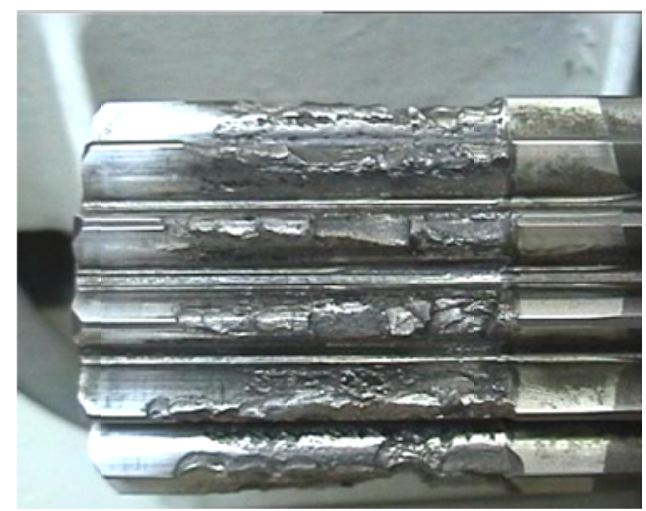

Fig. 4 Experimental results from test rig.

\section{Results-Practical Use of the Automated Calculation and Design Process}

\subsection{Design of a Saw Drive}

The first case study shows the automated design mode of the software MDESIGN gearbox. This allows creating a gearbox design automatically within a few seconds - utilizing as little as possible design parameters. The aim is to design a saw drive with 3
$\mathrm{kW}$ and an input speed of 1,500 rev/min. Fig. 5 below shows an exemplary fully automatic saw drive. On the right side, the manually refinished automated design of MDESIGN gearbox is shown.

The result of this design study is a number of possible gearboxes for different objectives like mass, design space or moment of inertia, Fig. 6.

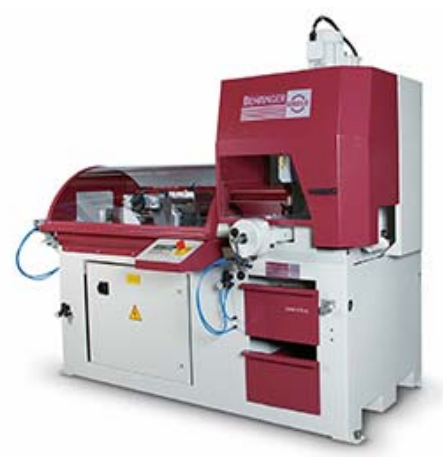

(a)

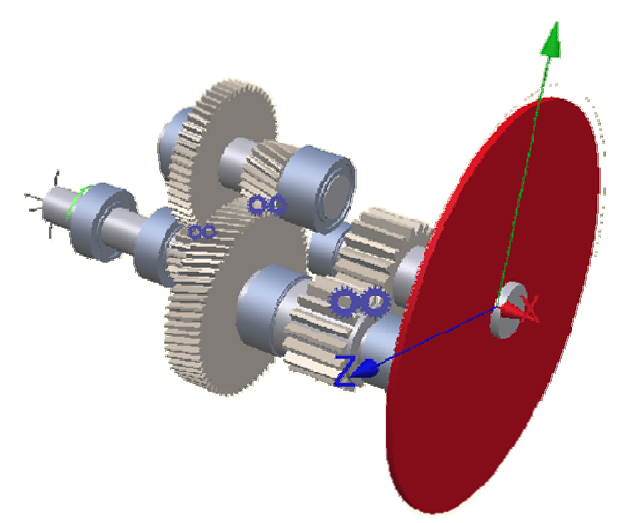

(b)

Fig. 5 (a) automatic saw drive and (b) MDESIGN gearbox model.

Source: www.behringer.net.

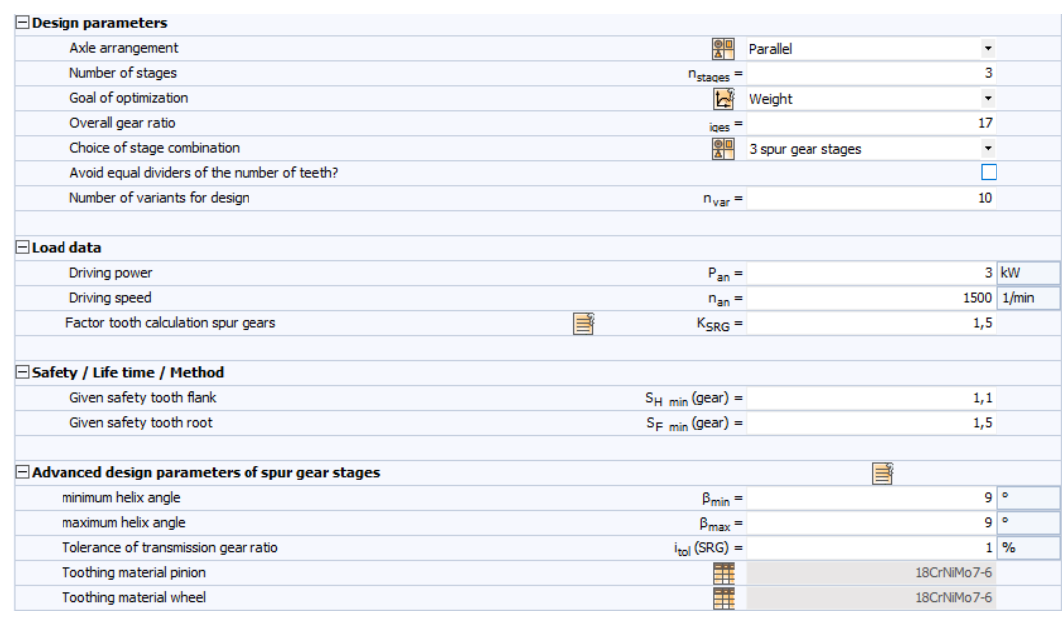

Fig. 6 Input parameters for automated design process MDESIGN gearbox. 

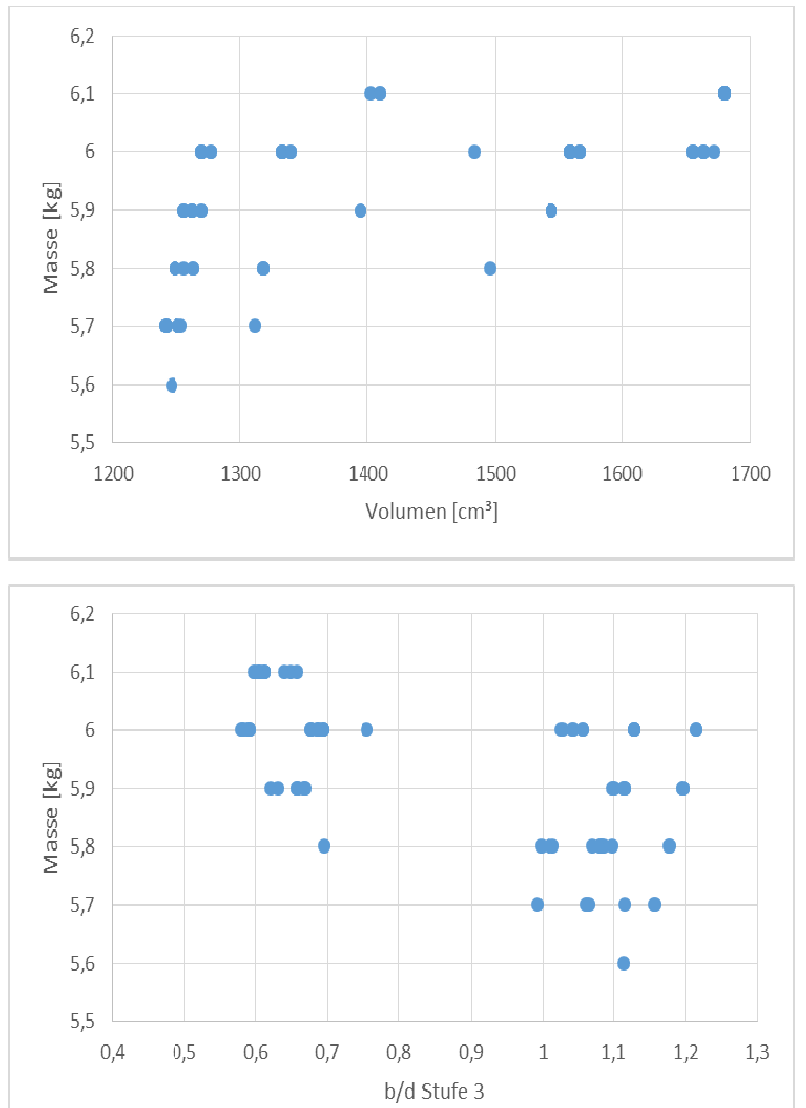

Fig. 7 Design results regarding the objective of minimal mass.

The following two visualizations show two solutions from across the variant field realizing the given design limits as a spur or helical geared design, Fig. 7.

The final decision which design represents the optimum solution for the specific task, can only be done by the experienced user. The software is a tool that can create a variety of solutions quickly. The decision must be done by the calculating engineer.

\subsection{Strength Verification and Documentation of an} Adjustment Gear System

Using the example of the adjustment gear system shown below, the calculation of the kinematic system as well as load calculation of MDESIGN gearbox shall be demonstrated. The major advantage is the consideration of the gearbox model as the sum of machine elements. Thus, it is possible to calculate all elements in a logical and coherent calculation process.
The finished calculation model will be analyzed on its kinematic conditions (torque, speed and power) at first, Fig. 9.

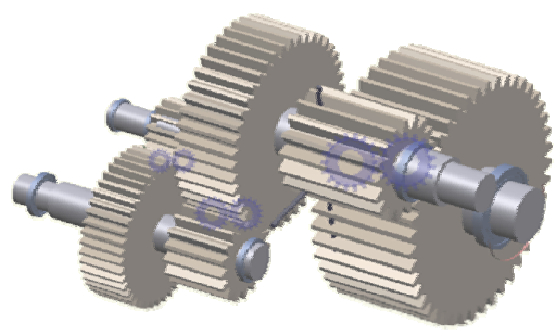

(a)

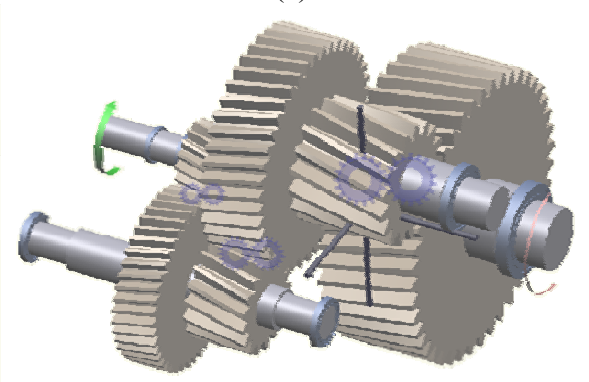

(b)

Fig. 8 Results of automated MDESIGN gearbox design: (a) spur gears and (b) helical gears.

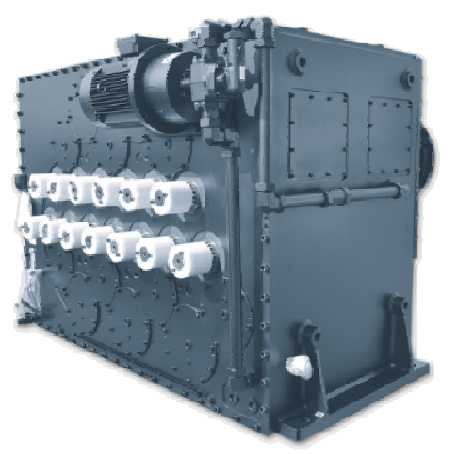

(a)

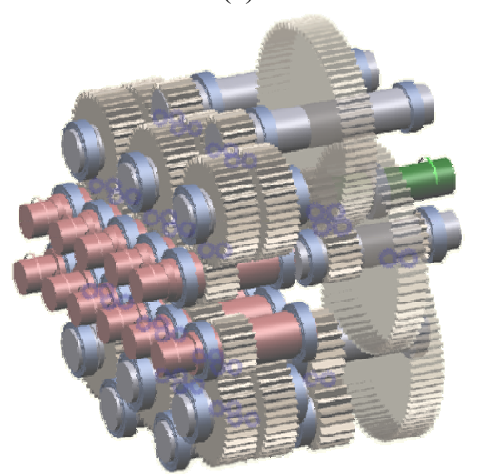

(b)

Fig. 9 Adjustment gear system: (a) existing design and (b) MDESIGN gearbox model. 


\begin{tabular}{ccccc} 
Kinematik & & & & \\
\hline Antrieb & Abtrieb & $\begin{array}{c}\text { Drehzahl } \\
{[1 / \mathrm{min}]}\end{array}$ & $\begin{array}{c}\text { Nennmoment } \\
{\left[\mathrm{N}^{*} \mathrm{~m}\right]}\end{array}$ & $\begin{array}{c}\text { Leistung } \\
{[\mathrm{kW}]}\end{array}$ \\
\hline Antrieb_01 & - & 1148 & 7236,84 & 870 \\
\hline & Abtrieb_01 & $-79,065$ & 104113,511 & $-862,027$ \\
- & Abtrieb_02 & $-79,065$ & 145,9 & $-1,208$ \\
- & Abtrieb_03 & $-79,065$ & 145,9 & $-1,208$ \\
- & Abtrieb_05 & $-79,065$ & 145,9 & $-1,208$ \\
- & Abtrieb_06 & 79,065 & $-175,1$ & $-1,45$ \\
- & Abtrieb_07 & 79,065 & $-175,1$ & $-1,45$ \\
- & Abtrieb_08 & 79,065 & $-175,1$ & $-1,45$
\end{tabular}

Fig. 10 Verification of gearbox kinematic—results (extract).

\begin{tabular}{|c|c|c|c|c|c|c|}
\hline \multicolumn{7}{|c|}{ Radpaare-Lasten } \\
\hline Radpaar & $\operatorname{Rad}_{1}$ & $\operatorname{Rad}_{2}$ & $\begin{array}{c}M_{1} \\
{\left[N^{2} m\right]}\end{array}$ & $\begin{array}{c}\mathrm{M}_{2} \\
{\left[\mathrm{~N}^{\mathrm{x}} \mathrm{m}\right]}\end{array}$ & $\begin{array}{c}\mathrm{n}_{1} \\
{[1 / \mathrm{min}]}\end{array}$ & $\begin{array}{c}n_{2} \\
{[1 / \text { min }]}\end{array}$ \\
\hline SR 3_SR4 & Stirnrad_3 & Stirnrad_4 & 24254,86 & 97019,439 & $-340,813$ & 85,203 \\
\hline SR21_SR22 & Stirnrad_21 & Stirnrad_22 & 121,864 & 487,458 & $-340,813$ & 85,203 \\
\hline SR23_SR27 & Stirnrad_23 & Stirnrad_27 & $-324,972$ & $-667,048$ & 85,203 & $-41,509$ \\
\hline SR23_SR24 & Stirnrad_23 & stimrad_24 & $-162,486$ & $-333,524$ & 85,203 & $-41,509$ \\
\hline SR25_SR 26 & Stirnrad_25 & Stirnrad_26 & 333,524 & 175,1 & $-41,509$ & 79,065 \\
\hline SR28_SR 30 & Stirnrad_28 & Stirnrad_30 & 333,524 & 175,1 & $-41,509$ & 79,065 \\
\hline SR28_SR 29 & Stirnrad_28 & Stirnrad_29 & 333,524 & 175,1 & $-41,509$ & 79,065 \\
\hline SR5_SR6 & Stirnrad_5 & Stirnrad_6 & $-97019,439$ & $-97019,439$ & 85,203 & $-85,203$ \\
\hline SR7_SR8 & Stirnrad_7 & Stirnrad_8 & 96748,66 & 198589,355 & $-85,203$ & 41,509 \\
\hline SR7_SR 12 & Stirnrad_7 & Stirnrad_12 & 270,779 & 555,81 & $-85,203$ & 41,509 \\
\hline SR9_SR 10 & Stirnrad_9 & Stirnrad_10 & $-198311,45$ & $-104113,511$ & 41,509 & $-79,065$ \\
\hline SR9_SR11 & Stirnrad_9 & Stirnrad_11 & $-277,905$ & $-145,9$ & 41,509 & $-79,065$ \\
\hline SR 13_SR14 & Stirnrad_13 & Stirnrad_14 & $-277,905$ & $-145,9$ & 41,509 & $-79,065$ \\
\hline SR13_SR 15 & Stirnrad_13 & Stirnrad_15 & $-277,905$ & $-145,9$ & 41,509 & $-79,065$ \\
\hline SR1_SR2 & Stirnrad_2 & Stirnrad_1 & $-24376,724$ & $-7236,84$ & $-340,813$ & 1148 \\
\hline
\end{tabular}

Fig. 11 Verification of gearbox kinematic_results (extract).

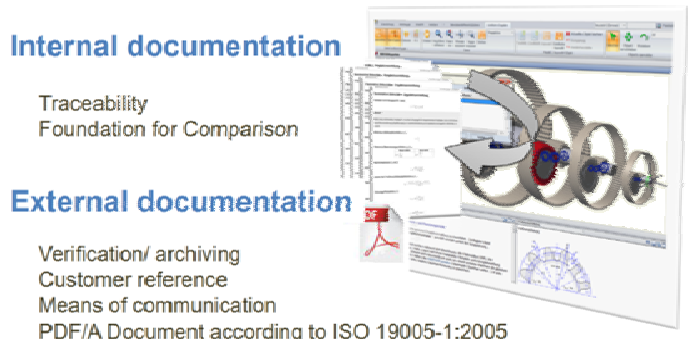

Fig. 12 Calculation documentation.

After the calculation of all machine parts, the documentation can be generated for a single element as well as for all parts combined.

The advantage of networked computing is, for example, the easy way of a change in input torque of \pm 10 percent and calculating all capacities, safety factors and lifetimes with the new requirements.

In this way, fast and qualified changes can be introduced and verified by calculation.

3.3 Optimization of the Load Distribution of Double Helical Geared Planetary Gearbox

Using the example of a turbo transmission, as used for example for coupling a gas turbine with a generator, this case study shows the possibilities of the micro-geometry optimization with MDESIGN LVR ${ }^{\text {planet }}$. 
Based on the modeled design in MDESIGN gearbox, you can export all parts to the load distribution calculation as well as any CAD system.

The following flowchart enables a brief overview of the calculation process. In the first step, the unmodified gears are analyzed in terms of the resultant load distribution. It shows expected unfavorable load conditions along the tooth flanks on the left and right gear side in both contacts (sun-planet and planet-ring gear) $[6,7]$.

Fig. 16 shows the maximum line loads and the ratio qmax/qavg following are noted:

Line load qmax/qavg

- Ring gear-planet left gear side: $2,031 \mathrm{~N} / \mathrm{mm}$

- Ring gear-planet right gear side:

$$
2,710 \mathrm{~N} / \mathrm{mm}
$$

- Sun-planet left gear side:

$$
2,134 \mathrm{~N} / \mathrm{mm}
$$

- Sun-planet right gear side:

$$
2,444 \mathrm{~N} / \mathrm{mm}
$$

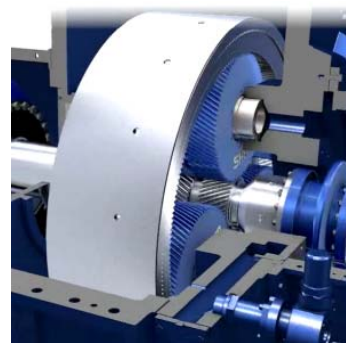

(a)

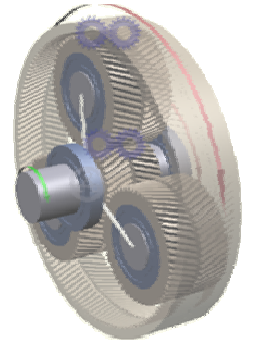

(b)
Fig. 13 Turbo transmission: (a) existing gearbox and (b) MDESIGN gearbox model.

Source: www.voith.com

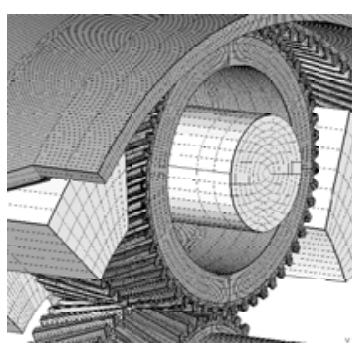

(a)

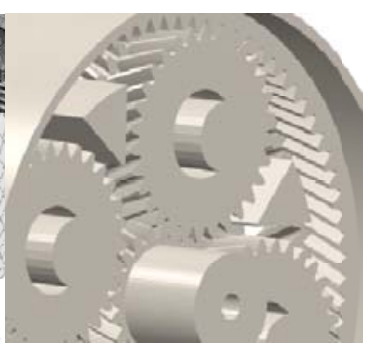

(b)
Fig. 14 Turbo transmission: (a) automated FE-model for integrated stiffness and deformation calculation and (b) export as CAD-model.
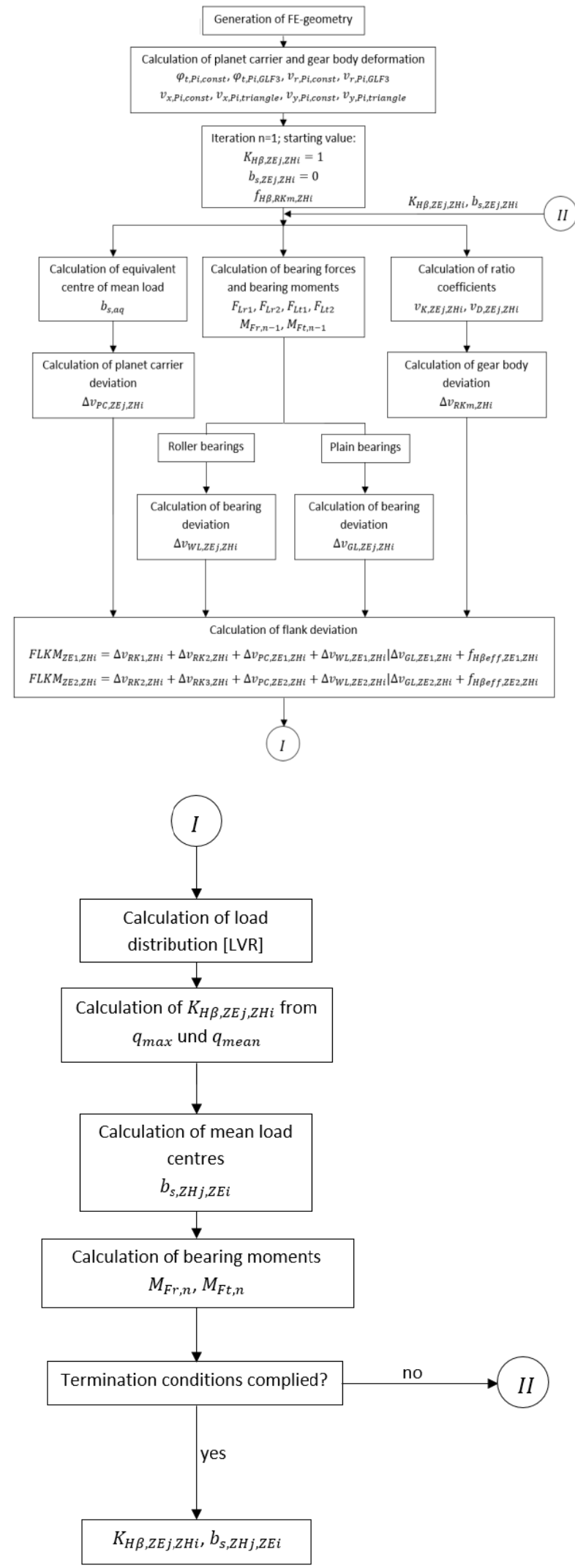

Fig. 15 Flowchart of the calculation process (extract) [13]. 
- = Eingriffsstrecke pro Teilung ${ }_{L} \_C=0.839$ ) eps_L $=2.80$

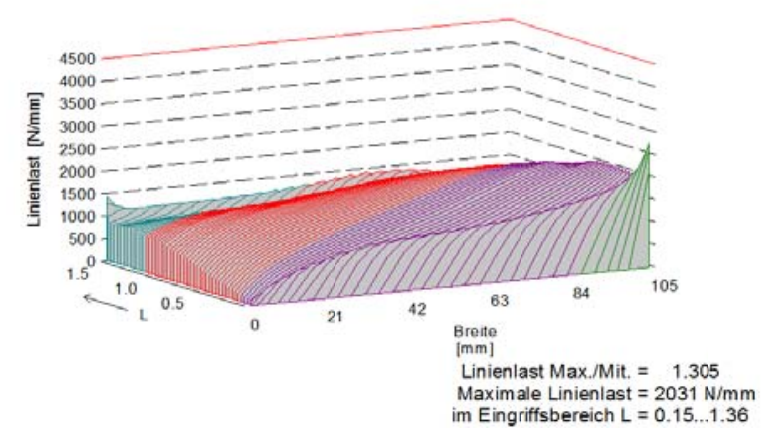

Ring gear-planet left gear side $L=$ Eingriffsstrecke pro Teilung
$\left(L \_C=0.839\right)$ eps_L $=2.80$

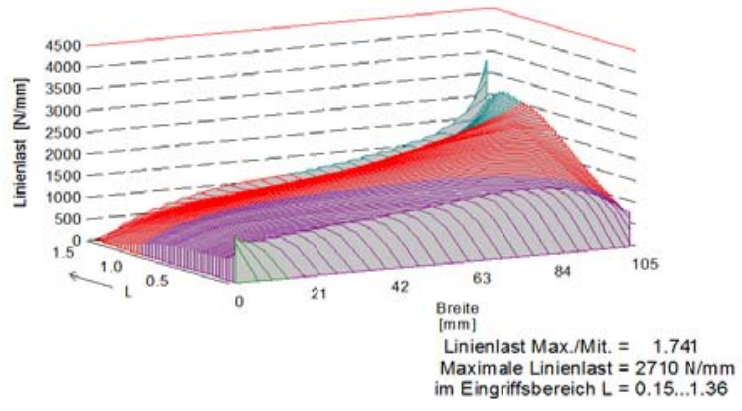

Ring gear-planet right gear side

$\mathrm{L}=$ Eingriffsstrecke pro Teilung
$(\mathrm{L} C \mathrm{C}=0.669)$ eps $\mathrm{L}=2.43$

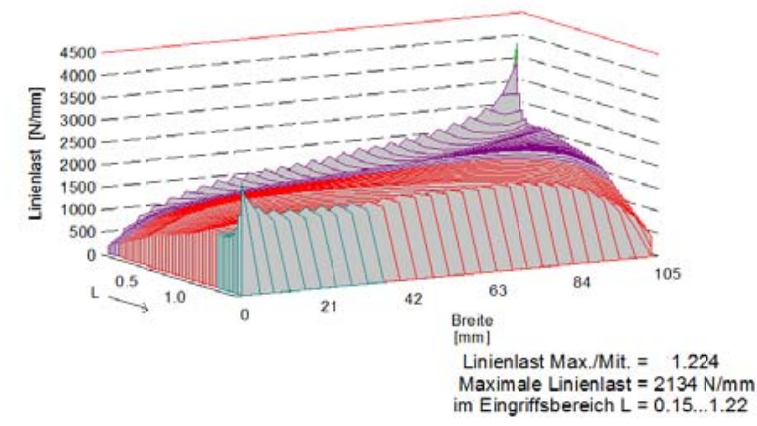

Sun-planet left gear side

$L=$ Eingriffsstrecke pro Teilung
$\left(L \_C=0.669\right)$ eps_L $=2.43$

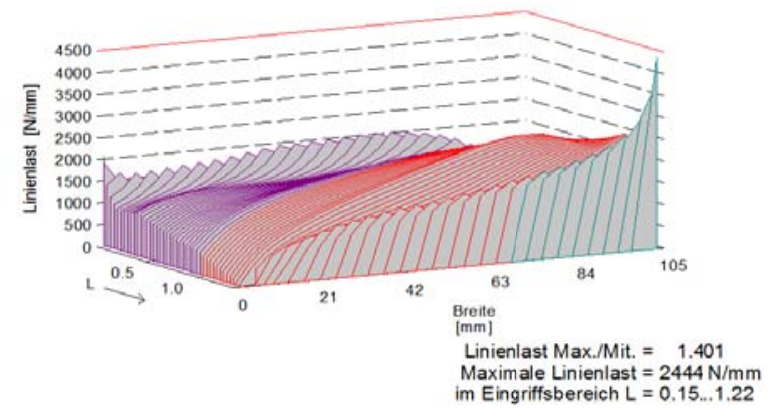

Sun-planet right gear side

Fig. 16 Results of load distribution-line load, unmodified.
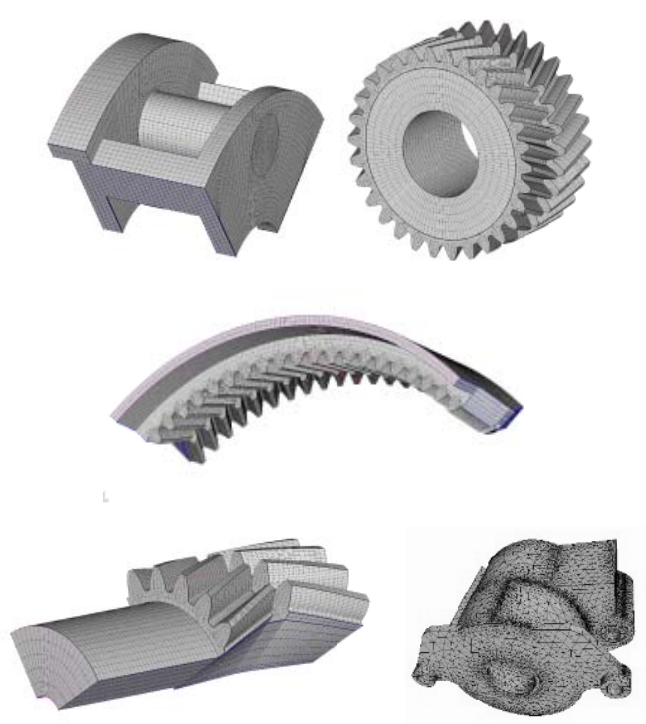

Fig. 17 FE-models for integrated stiffness calculation and analyze, bottom: external FE-model of housing calculation.

Due to the now present knowledge of the deformation behavior, the optimal flank modifications can now be evaluated by the software, Fig. 18.

The related contact patterns in the field of contact are shown in Fig. 19.
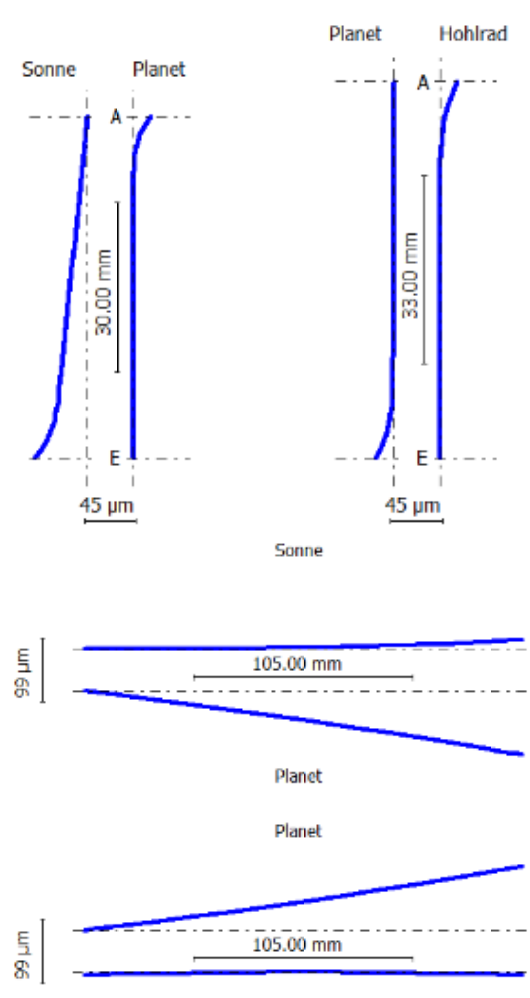

Hohirad

Fig. 18 Modification in lead and profile direction for constant load distribution along the field of contact. 


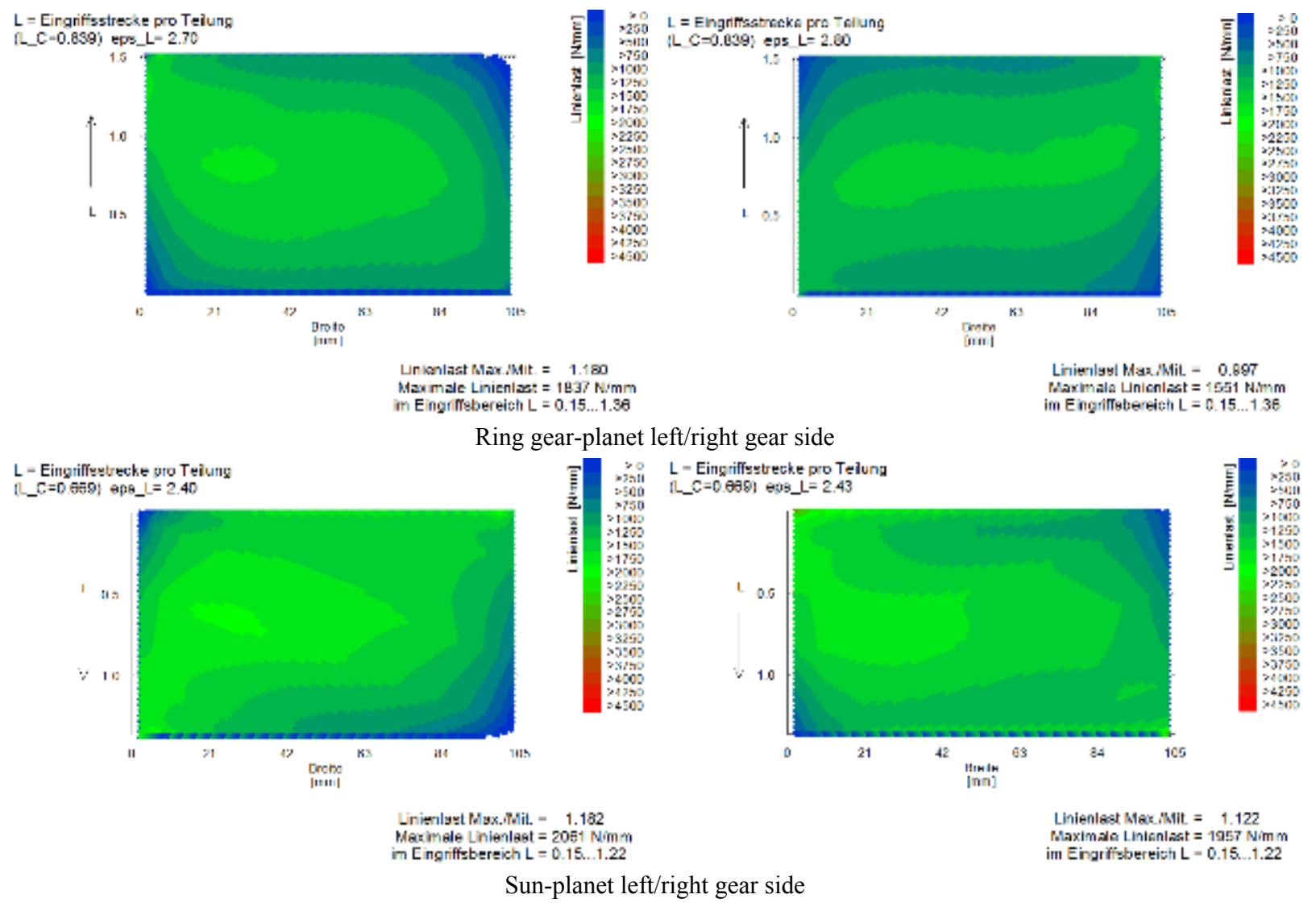

Fig. 19 Results of load distribution, contact pattern.

Regarding the results shown in Figs. 18 and 19, the reduced line loads and ratio of maximum to average load can be presented:

Line load qmax/qavgimprovement

Ring gear-planet left gear side: $1.18 \quad-10 \%$

Ring gear-planet right gear side: $1.00 \quad-43 \%$

Sun-planet left gear side: $\quad 1.18 \quad-3 \%$

Sun-planet right gear side: $\quad 1.12 \quad-20 \%$

The improvement in percentage shows the possibility of using the material and available space as good and effective as possible. It is important to note that this modification may only be the optimal variant for this load case, other load cases or even a load spectrum must be checked and evaluated separately.

The chosen modifications should always be interpreted in terms of what influence parameters were included in the calculation process - the more deformation and stiffness parameters included the better is the result for the flank modification. Ignoring elements and their stiffnesses or deformations like planet carrier, gear wheel, bearing or planet pin deformation can also lead to modification that seem to help but maybe cause opposite effects.

\section{Conclusions}

Gearbox designs are highly depending on the application. What all gearboxes have in common is the need of strength verification according to official standards like DIN, AGMA, ISO, VDI etc. The number of machine elements and needed calculation methods (FEM, numerical and analytical, etc) complicates the process for the executing engineer. Realizing this calculation process in an automated algorithm creates the possibility to cover the development process from design to verification with a maximum of transparency combined with a low potential of errors. 


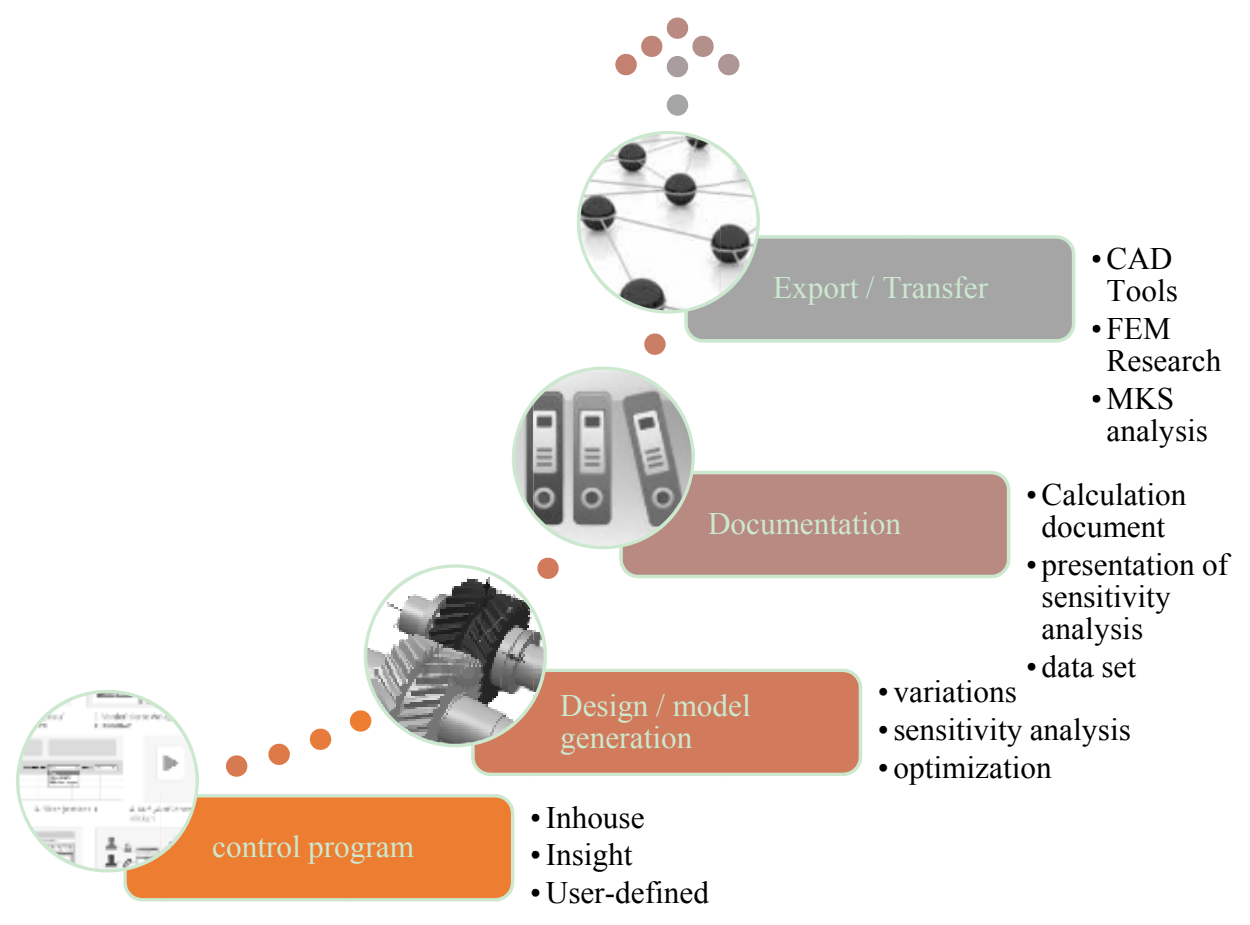

Fig. 20 MDESIGN integrated into CAx-Process.

This time efficient calculation process in its practical use also provides the opportunity of further researches. As an example, the research of tooth contact analysis for double helical gears is done with this algorithm, evaluating the influence of design parameters like the groove width and depth between the gear sides. This way, design specific influences may be considered that are only approximated in calculation standards. Having the opportunity of serial calculations enables the examination of additional influences, taking into account mounting and manufacturing conditions or checking the efficiency and profitability by comparing different designs, materials, loads and conditions.

The calculation results shown in chapter 3 prove the ability of the process to operate in diverse applications. New designs could be created and transformed into a closed calculation beginning from the gearbox kinematics until verification and optimization process automatically, regarding all the relevant influences of surrounding and correlating elements. Using detailed routines for all elements also enables the use of the best calculation method integrated in the calculation standards (e.g., method A/ISO6336). As a result of the calculation, there will be a statement to the sustainability and capacity of the whole system - not only specific parts of isolated element calculations. Utilizing this closed calculation and all interactions between the machine elements different influences of single elements to the "system gearbox" can be derived.

According to the product development process shown in the introduction, a gearbox calculation software cannot be separated. Rather, the analysis of the capacities, safety factors and lifetimes only represents one step in the entire process. An interface management is an almost mandatory requirement to integrate a calculation software into the whole CAx-process.

The software package MDESIGN could prove different tasks, such as being a flexible and easy software platform in cooperation with other necessary tools. Realized solutions include:

- Composite idlers and pulleys calculation with 
shaft verification, calculation of weld seams and fully integrated commercial FEM solver and access to PLM system;

- Fully automated planetary gearbox calculation as CAx process without user intervention. This is done exclusively through commercial ERP (Enterprise-Resource-Planning) control software controlling MDESIGN in batch mode.

For the future, it remains desirable that the analytical calculation packages continue to merge with the other CAx tools. This is a significantly more efficient CAx process to realize without unnecessary errors or transmission failures [12].

\section{References}

[1] Schulze, T. 2011. "Effektives Getriebedesign mehrstufiger Getriebe-Ausschöpfung des gesamten Potenzials." Presented at the Vortrag DMK 2011, Dresden, Germany.

[2] DIN 3990:1987 Tragfähigkeitsberechnung von Stirnrädern.

[3] DIN 743:2008 T1-T4 \& Beiblatt 1,2 Tragfähigkeitsberechnung von Wellen und Achsen.

[4] DIN ISO 281:2009 Wälzlager-Dynamische Tragzahlen und nominelle Lebensdauer-Berechnung der modifizierten nominellen Referenz-Lebensdauer für
Wälzlager.

[5] ISO 6336:2008 Calculation of load capacity of spur and helical gears.

[6] Linke, H. 1996. Stirnradverzahnung-Berechnung, Werkstoffe, Fertigung. München, Wien: Hanser.

[7] Schlecht, B., and Schulze, T. 2009. Hartmann-Gerlach, C.: Berechnung der Lastverteilung in Planetengetrieben unter Berücksichtigung aller relevanten Einflüsse-Zeitschriftenbeitrag Konstruktion 06/2009 S12.ff, DriveConcepts GmbH.

[8] Schulze, T., and Hartmann-Gerlach, C. 2010. Auslegung \& Optimierung von mehrstufigen Getrieben-Vortrag anlässlich des Schweizer Maschinenelemente Kolloquium SMK2010 in Dresden, DriveConcepts $\mathrm{GmbH}$.

[9] MDESIGN LVR 2016. Software zur Beanspruchungsanalyse evolventischer Stirnradgetriebe, DriveConcepts GmbH.

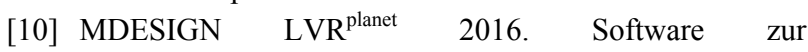
Beanspruchungsanalyse von Planetenradgetrieben, DriveConcepts GmbH.

[11] MDESIGN gearbox 2016. Software für Design und normgerechten Nachweis von Getrieben, DriveConcepts $\mathrm{GmbH}$.

[12] Polyakov, Denis. Design Process Management-Ein systematischer Ansatz zur Durchführung komplexer Maschinenelementeberechnungen.

[13] Sibber, E. 2015. Lastverteilungsrechnung von Doppelschrägverzahnungen in Planetengetrieben, Belegarbeit bei DriveConcepts GmbH. 